\title{
O turismo como vetor das relações Brasil-Argentina nas décadas de 1920 e 1930
} Valeria Lima Guimarães ${ }^{1}$

\section{Resumo}

Neste artigo serão analisadas as iniciativas governamentais e de atores da sociedade civil brasileira, no sentido de incrementar o turismo internacional como estratégia de aproximação com outros países. Será dado destaque aos argumentos favoráveis ao desenvolvimento da atividade turística entre os vizinhos, especialmente a Argentina, e aos entraves encontrados para a sua realização. Verifica-se, ao longo do estudo, que os discursos que conformam a aproximação turística do Brasil com outras nações estavam fortemente influenciados por uma crença generalizada de que tal atividade econômica seria uma das mais novas e promissoras fontes de obtenção de divisas para um país. Constata-se ainda a influência do ideário pan-americanista no incentivo ao intercâmbio turístico intrarregional e a busca do protagonismo das duas nações líderes, na América do Sul, na organização desse novo turismo.

Palavras-chave: turismo, relações Brasil-Argentina, pan-americanismo.

\begin{abstract}
In this article, governmental initiatives from Brazilian civil society's protagonists will be analyzed toward increasing international tourism as an approaching strategy with other countries. We highlight the favorable arguments for tourist activity development among neighbors - especially Argentina - as well as the barriers to its accomplishment. Throughout the study we verify that the speeches conforming Brazilian tourist approaching to other nations have been strongly influenced by a generalized belief that such economic activity would be one of the most promising sources of foreign exchange earnings for a country. We also notice the influence of the pan-Americanism idea on the incentive of intra-regional tourist interchange and the search of the role that two leading nations in South America will play in the organization of this new tourism.
\end{abstract}

Key-words: tourism, Brazil-Argentina relationship, pan-Americanism.

\footnotetext{
${ }^{1}$ Doutora em História Comparada pela Universidade Federal do Rio de Janeiro. Professora do Departamento de Turismo da Universidade Federal Fluminense (UFF), Brasil. Atualmente pesquisa a história do turismo nos países do continente americano em perspectiva comparada. E-mail: valeria@turismo.uff.br

Revista Eletrônica da ANPHLAC, ISSN 1679-1061, n.15, p. 175-197, jul./dez. 2013. 
Artigo recebido em: 30/06/2013

Artigo aprovado em: 14/09/2013

\section{Introdução}

O objetivo principal deste trabalho, desenvolvido no campo da história, é buscar contribuir para uma historiografia do turismo brasileiro, objeto pouco valorizado pelos estudos acadêmicos, chamando atenção para a sua relevância no desenvolvimento das relações do Brasil,a partir da primeira metade do século XX,com outros países, particularmente a Argentina.

Para pensar as conexões entre o turismo e as relações internacionais foram inspiradoras as reflexões surgidas nas últimas décadas, trazidas por autores como Gerson Moura (1984), Mônica Herz (1988), José Flávio Sombra Saraiva (2001), Hugo Suppo (2007) e Mônica Lessa (2002; 2007), entre outros, que ajudaram a ampliar o olhar sobre as relações internacionais no Brasil, valorizando a dimensão cultural, até então pouco prestigiada, em razão dos paradigmas predominantes, centrados nos jogos de poder e nos interesses e conflitos envolvidos no equilíbrio entre guerra e paz.

$\mathrm{O}$ recorte escolhido para o estudo que se apresenta focaliza os entendimentos travados entre governos, sociedade civil e organismos supranacionais de turismo, nas primeiras décadas do século XX, interessados no intercâmbio turístico entre os cidadãos como estratégia de desenvolvimento econômico e de estreitamento da amizade entre os povos, com ênfase nas relações turísticas entre Brasil e Argentina.

O corpus documental do trabalho é composto de um conjunto variado de fontes, dentre elas a correspondência diplomática trocada entre o Brasil e diversos países, tendo como pauta o desenvolvimento do turismo, disponível no Itamaraty e nos arquivos da chancelaria argentina; jornais diários de grande circulação nesses países,dentre os quais se citamLa Nación, Jornal do Brasil, Correio da Manhã e os dois jornais do grupo paulistano Folha (Folha da Manhã e Folha da Noite); revistas especializadas em turismo, como Automovilismo, a revista do Automóvil Club Argentino (ACA), Turismo, o periódico do Touring Club Argentino, e Brasil, Paiz de Turismo, publicada no Brasil, com circulação em vários países, inclusive a Argentina.

Revista Eletrônica da ANPHLAC, ISSN 1679-1061, n.15, p. 175-197, jul./dez. 2013. 
Trata-se de um período de grande instabilidade global, caracterizado pela crise econômica de 1929e do liberalismo, pelo avanço das ideologias nazifascistas, pelo aumento do aparato de controle e vigilância nas alfândegas e fronteiras e pela iminência e deflagração da Segunda Guerra Mundial. Nesse quadro conjuntural, ganhava maior vigor nas Américas, o ideal pan-americanista, estruturado em associação com a Doutrina Monroe.

Acreditava-se que, além do incremento da economia dos países receptores, o turismo, qualquer que fosse a motivação (mas especialmente aquele provocado pelos interesses de intercâmbio cultural), assumiria também um importante papel de agente de promoção das relações cordiais entre as nações, sendo Brasil e Argentina os principais porta-vozes desses discursos no subcontinente.

\section{Os primeiros acordes do interesse brasileiro pelo turismo internacional}

No final da década de 1920 e início dos anos 1930, entre as alarmantes notícias e editoriais sobre a conjuntura internacional, nossos principais jornais começavam a incluir em sua pauta dados estatísticos referentes aos resultados econômicos advindos da atividade turística nos principais destinos mundiais, dentre eles Itália, França, Espanha, Alemanha e Estados Unidos. De acordo com os periódicos brasileiros, a atividade turística seria uma espécie de tábua de salvação para a economia dos países receptores, que tivessem investido em infraestrutura para receber os cada vez mais numerosos viajantes a lazer.

Ao mesmo tempo em que destacavam a importância dada ao turismo por aquelas nações como uma alternativa à crise econômica mundial, os periódicos brasileiros ressentiam-se, em matérias assinadas e editoriais, da falta de organização do setor e do despreparo de nossos governantes, que ignoravam a pauta do turismo na agenda pública estatal.

Cobravam ações mais enérgicas das três esferas de governo em relação à criação de uma infraestrutura para o nosso turismo receptivo, cujo maior recurso era a natureza, vista como exuberante e exótica. O Brasil estaria desperdiçando, então, um imenso potencial para a exploração turística em várias regiões de seu território, particularmente naquelas em que se concentravam nossos maiores rios e as maiores

Revista Eletrônica da ANPHLAC, ISSN 1679-1061, n.15, p. 175-197, jul./dez. 2013. 
quedas d'água, como a Amazônia, as Cataratas de Foz do Iguaçu e o extinto Salto de Sete Quedas, ambos no Paraná.

A oferta do incipiente turismo brasileiro daquela época fora organizada de forma concentrada na capital federal, elegendo como público-alvo preferencial os visitantes estrangeiros provenientes dos grandes centros mundiais, e como principais atrativos as construções que resultaram das reformas urbanas inspiradas na Belle Époque francesa. As edificações, os trabalhos de urbanização e paisagismo e os monumentos erigidos à época serviriam como nossos principais cartões de visita para impressionar positivamente os forasteiros originários dos países centrais, que levariam consigo imagens de uma nação que pretendia ser percebida como próspera, civilizada e moderna.

A relação entre a construção de uma imagem moderna do Brasil e o turismo como estratégia de propaganda da nação pode ser analisada pelo viés de dois dos mais importantes eventos internacionais na primeira metade do século XX: a Exposição do Centenário da Abertura dos Portos (1908) e a Exposição Internacional comemorativa do Centenário da Independência do Brasil (1922), tema que foi aprofundado por Machado (2007).

Pode-se argumentar que, no início da década de 1920, quando o turismo brasileiro dava os seus primeiros passos acompanhando os esforços de entrada do país na modernidade, fazia todo o sentido investir no turismo receptivo internacional, tendo como chamariz as celebrações do centenário de 1822, cujo ápice foi a Exposição Internacional, que durou de setembro de 1922 a julho de 1923. Os festejos, especialmente a Exposição Internacional, com seus suntuosos pavilhões arquitetados para a ocasião, tiveram caráter monumental, justamente para atrair e bem impressionar não só os visitantes domésticos, como também os estrangeiros, dentre os quais pessoas de alta distinção, chefes de Estado e comitivas oficiais ${ }^{2}$.

\footnotetext{
${ }^{2}$ Segundo o presidente Epitácio Pessoa, enviaram missões presididas por embaixadores especiais: a Santa Sé, Estados Unidos, Portugal, França, Inglaterra, Bélgica, México, Chile, Itália, China, Japão, Colômbia, Tchecoslováquia, Uruguai, Alemanha, Argentina, Bolívia, Peru e Equador. Cuba, Noruega, Panamá, Suécia, Venezuela, Suíça, Polônia, Holanda, Dinamarca, Bulgária, Guatemala, Nicarágua, El Salvador e Honduras se representaram pelos seus plenipotenciários acreditados no Brasil. Inglaterra, Estados Unidos, Japão, México, Argentina e Uruguai enviaram vasos de guerra. O destaque ficou por conta da presença do presidente português, Antonio José de Almeida, que protagonizou "um dos acontecimentos mais notáveis" da Exposição (PESSOA, 1922, p.25).
}

Revista Eletrônica da ANPHLAC, ISSN 1679-1061, n.15, p. 175-197, jul./dez. 2013. 
Para acomodá-los, foram construídos luxuosos hotéis, como o Hotel Glória e o Copacabana Palace, que, apesar dos esforços, não ficou pronto a tempo. Era estratégico bem receber e difundir uma imagem positiva da nação no exterior, na medida em que o Brasil pleiteava obter maior prestígio e reconhecimento internacional, particularmente no que se refere à mudança de seu status na Liga das Nações, almejando ascender de membro temporário a permanente no Conselho da Liga (JESUS; GUIMARÃES, 2012).

Num balanço de seu governo, cujo término se deu em pleno período dos festejos do Centenário, Epitácio Pessoa destacou o sucesso dessas comemorações na consolidação da imagem pretendida do Brasil no exterior:

O Brasil tem razão para sentir-se orgulhoso da commemoração do seu
Centenário. A presença no Rio de Janeiro de representantes de todos os
paizes cultos do mundo attesta a nossa lisonjeira situação internacional; o
esplendor da Exposição é prova, surprehendente para os estrangeiros e
mesmo para os brasileiros, do desenvolvimento das nossas indústrias, da
exuberância da nossa produção, da variedade das nossas riquezas, do
admirável progresso que realizamos nestes cem annos de vida independente.
De delegado de uma das maiores pretensoras nações da Europa ouvi que a
Exposição do Rio de Janeiro fora para elle origem de grande decepção:
esperava encontrar no Brasil um vasto mercado de consumo para as
indústrias do seu paiz, e acabava de verificar que esse mercado possuía na
produção nacional tudo de que necessitava. (PESSOA, 1922, p.12).

A experiência de 1922 serviu para afirmar a importância do turismo como forma de divulgação da nação, de captação de divisas e de ganhos políticos para o país. Dessa maneira, poucos meses depois do término dos festejos do Centenário, foi criada a Sociedade Brasileira de Turismo. Até hoje em funcionamento, essa entidade privada e sem fins lucrativos logo assumiu o protagonismo na organização do turismo brasileiro. Imbuída do que considerava ser a sua "missão patriótica", essa nova organização dedicou-se a "revelar o Brasil para os brasileiros", por meio de suas excursões rodoviárias e fluviais e da publicação de periódicos especializados na divulgação do turismo doméstico, como a Revista Brasileira de Turismo, o seu órgão oficial, cuja publicação teve início em 1924.

Conforme se pode constatar na leitura da revista, àquela altura faltava-nos de tudo para o desenvolvimento da atividade turística no país. Apesar da difusão do automóvel e das novas práticas de passeios nesses veículos, não havia infraestrutura

Revista Eletrônica da ANPHLAC, ISSN 1679-1061, n.15, p. 175-197, jul./dez. 2013. http://revista.anphlac.org.br/ 
viária adequada para as viagens, eram raros os bons equipamentos de hospedagem e já era sentida a falta de pessoal qualificado para a prestação de serviços em turismo (inclusive com o domínio de outros idiomas), além da má qualidade dos transportes turísticos em geral.

Desde a sua criação, a Sociedade Brasileira de Turismo procurou empreender melhorias viárias, implantando a sinalização turística nas estradas, produzindo mapas rodoviários e pressionando os governos a incluírem a pauta do turismo na agenda pública, tendo como maior reivindicação a normatização do setor. Também chamou para si a responsabilidade de representar o país no exterior, nos assuntos que envolviam o turismo. Em virtude de seus projetos de internacionalização, ao associar-se ao Touring Club, com sede na França, a partir de 1926, a Sociedade Brasileira de Turismo passou a adotar o nome de Touring Club do Brasil (TCB).

Por um longo período, o TCB foi responsável pelo emplacamento e registro de veículos no país, inclusive dos automóveis estrangeiros que entravam no Brasil a turismo ou dos brasileiros que circulavam no exterior com essa finalidade. Ao assumira tarefa de organizar o turismo nacional, o Touring recebeu do governo federal poderes para recepcionar os turistas domésticos e internacionais, no então principal portão de entrada no país, o porto do Rio de Janeiro.

Na correspondência diplomática disponível no Arquivo Histórico do Itamaraty e indexada sob o título de "turismo", é possível ver as relações estabelecidas entre o agora Touring Club do Brasil, a Prefeitura do Distrito Federal e o Ministério das Relações Exteriores, no sentido de ser essa organização civil a representante oficial do governo brasileiro, em vários certames internacionais ligados ao turismo, como congressos e feiras, ao longo das décadas de 1920 e 1930.

Essa preponderância do Touring brasileiro nos assuntos turísticos que envolviam o Estado devia-se à falta de um órgão público específico para cuidar do turismo, o que só seria remediado a partir de 1934, com a criação do Departamento Geral de Turismo, ligado à Prefeitura do Distrito Federal, e melhor estruturado em 1937, com a estratégica inclusão de uma Divisão de Turismo numa das principais agências do Estado Novo, o Departamento de Imprensa e Propaganda. Ressalta-se ainda que, à frente desses dois departamentos que incluíram a promoção do turismo entre as suas principais Revista Eletrônica da ANPHLAC, ISSN 1679-1061, n.15, p. 175-197, jul./dez. 2013. 
incumbências, esteve Lourival Fontes, uma das figuras centrais da montagem do regime estadonovista. Isso nos permite falar numa visão estratégica do chefe do DIP acerca do turismo como um dos elementos primordiais na veiculação da propaganda da nação, dentro e fora do país.

Por sua vez, o Touring Club promovia excursões internacionais a destinos como os Estados Unidos e os países platinos, além de colaborar no processo de oficialização do carnaval carioca pela Prefeitura do Distrito Federal, em 1932. Atuou, inclusive, na organização dos festejos por vários anos seguidos, cujo ponto alto era o Baile de Gala do Theatro Municipal, realizado em homenagem aos turistas estrangeiros e nacionais, vindos ao Rio para participar da folia carnavalesca.

\section{O estreitamento das relações turísticas entre o Brasil e a Argentina e os projetos de integração continental pela via do turismo}

O Touring Club do Brasil participou ativamente do Primeiro Congresso SulAmericano de Turismo, realizado em 1928, em Buenos Aires. Nessa ocasião, tornou-se membro fundador da Federação Sul-Americana de Turismo, com sede na capital portenha. A federação era formada pelo Touring Club Argentino e pelo Touring Club do Brasil, contando ainda com representantes da Colômbia, do Chile, do Equador, do Panamá, do Paraguai, do Peru, do Uruguai e da Venezuela.

Conforme a historiadora argentina Melina Piglia (2008), a crise econômica e as crises políticas nos países sul-americanos dificultaram o funcionamento regular da nova organização turística regional. Ainda assim, ao longo de sua existência, foram promovidos pela federação três congressos interamericanos de turismo, que proporcionaram a troca de informações técnicas sobre o turismo e a política viária entre os membros participantes e a tomada de decisões conjuntas sobre essas matérias (PIGLIA, 2008).

Em relação ao caso argentino, a autora analisou que os congressos serviram também para dar maior legitimidade política aos seus participantes junto ao Estado e à opinião pública e deram lugar a organismos permanentes, que ora interpelavam o Estado, ora realizavam atividades conjuntas. Conforme Guimarães (2012), essa análise também pode ser aplicada ao caso brasileiro, particularmente no que diz respeito às Revista Eletrônica da ANPHLAC, ISSN 1679-1061, n.15, p. 175-197, jul./dez. 2013. 
pretensões do Touring Club do Brasil, que foi designado pelo Itamaraty em 1934 como Órgão Oficial para o Fomento do Turismo na América do Sul.

As ousadas recomendações dos congressos organizados pela federação incluíam, por exemplo, um plano de coordenação das vias terrestres e marítimas com os países vizinhos e a formação de cooperativas de turismo incumbidas de facilitar aos universitários, educadores, empregados, comerciantes, industriais e operários os meios necessários para que pudessem usufruir dos benefícios do turismo ${ }^{3}$. Sob os auspícios do novo organismo continental, foram organizados, inclusive, vários cruzeiros ao Brasil e ao Paraguai (PIGLIA, 2008). Além da cooperação técnica e econômica, a Federação Sul-Americana afinava-se aos discursos de integração continental, presentes no ideário pan-americanista, por meio do turismo, tendo defendido até a inclusão do turismo sulamericano nos currículos escolares, bem como apoiado as ideias de revisão dos textos de história e geografia que soassem ofensivos aos países sul-americanos (PIGLIA, 2009). De acordo com a publicação do Touring Clube Argentino, a Federação SulAmericana de Turismo foi o embrião de um projeto maior, postulado pela União PanAmericana ${ }^{4}$, com vistas à criação de organismos similares na América do Norte, na América Central e nas Antilhas, que posteriormente formariam a Confederação PanAmericana de Turismo.

Em 1929, uma excursão de turistas brasileiros, incluindo vários jornalistas, partiu a bordo do paquete Almirante Jaceguay, com destino a Buenos Aires. Na despedida do país vizinho, com direito à festa no porto, organizada por representantes da Federação Sul-Americana de Turismo e do Touring Club Argentino, um dos turistas, de nome Amílcar Marchesini, fez o seguinte pronunciamento:

Essas embaixadas de um povo a outro povo, sem as pragmáticas e a fórmula diplomática, aproximam realmente os países, como é o caso atual do Brasil e da Argentina, cada vez mais inquebrantavelmente unidos, graças em grande

\footnotetext{
${ }^{3}$ Tais recomendações resultaram do congresso de Lima, em 1929, e foram relatadas pela Folha da Manhã, na edição de 10 de novembro de 1929, à página 28, sob o título de "Uma medida no Congresso SulAmericano de Turismo".

${ }^{4}$ A União Pan-americana foi criada em 1890, no conjunto das iniciativas que deram origem ao panamericanismo liderado pelos Estados Unidos. Na década de 1940, contava com 21 países membros. Em 1935, foi criada sua Divisão de Turismo, com a finalidade de promover a aproximação e o desenvolvimento turísticos nos países do continente. Em 1952,o organismo multilateral foi transformado em Secretaria Geral, com a criação da Organização dos Estados Americanos (OEA).
}

Revista Eletrônica da ANPHLAC, ISSN 1679-1061, n.15, p. 175-197, jul./dez. 2013. 
parte, a essa corrente recíproca de viajantes e turistas de ambos os países. (Folha da Manhã, 30 de novembro de 1929, capa)

Pelo lado argentino, o representante da Federação Sul-Americana de Turismo enalteceu o trabalho de pan-americanismo prático realizado pela instituição e pediu aos jornalistas integrantes da excursão ampla divulgação dos trabalhos da Federação no Brasil.

A integração turística entre os países americanos esteve presente também na concepção do Centro Turístico das Três Fronteiras, envolvendo o Brasil, a Argentina e o Paraguai, com epicentro em Foz do Iguaçu. Fundado e presidido por um juiz de direito que atuava na localidade, em 1929, eram objetivos do Centro a criação de um grande hotel cassino e a construção de um Parque Nacional, onde seria erigido um monumento à paz e à fraternidade entre os povos vizinhos (Folha da manhã, 8 de novembro de 1929, p.3).

As relações de amizade e de aproximação turística entre Brasil e Argentina, em especial, como tem sido ressaltado, não se restringiam à iniciativa governamental, envolvendo diversos atores da sociedade civil. Chega a ser difícil delimitar se eram de caráter público ou privado, tamanha a interpenetração das duas esferas no caso do turismo, o que também foi sentido pela historiadora Melina Piglia (2008),no estudo do turismo argentino. Mas o fato é que o Estado seria beneficiário de todas essas relações travadas entre os dois países, na medida em que elas difundiam uma imagem positiva da nação e o estreitamento de laços entre grupos das duas nações (LESSA, 2002).

\section{O convênio de turismo firmado entre Brasil e Argentina}

$\mathrm{Na}$ década de 1930, ainda que a histórica rivalidade política e o clima de desconfiança mútua entre Brasil e Argentina persistissem, começavam-se a ampliar os espaços de cooperação entre essas sociedades. Tal rivalidade, que, se investigada a fundo remonta à colonização e à disputa por possessões e prestígio entre portugueses e espanhóis no subcontinente, ganhou contornos dramáticos no período pósindependência dos dois países, tendo na Guerra da Cisplatina (1825-1828) um dos momentos críticos da hostilidade mútua. A acirrada competição entre as duas nações

Revista Eletrônica da ANPHLAC, ISSN 1679-1061, n.15, p. 175-197, jul./dez. 2013. 
pela hegemonia política e econômica na região ao longo do século XIX alimentou o clima de desconfiança entre ambos.

A nova fase das relações bilaterais entre os antigos adversários, inaugurada no início do século $\mathrm{XX}$, foi motivada pela busca da cooperação para superar as sérias dificuldades provocadas pela crise de 1929, nesses dois países de economia agrárioexportadora. Um dos marcos mais significativos da mudança de paradigma nas relações entre Brasil e Argentina foi a visita do presidente Augustín Justo (1932-1938), com o chanceler Saavedra Lamas (1932-1938), à nação vizinha, em outubro de 1933 (SANTOS, 2008).

Junto com a emblemática visita do presidente argentino ao Brasil em 1933, diversos acordos políticos e econômicos foram firmados entre as duas nações, bem como se intensificaria, a partir desse momento, a promoção do intercâmbio cultural, proporcionado tanto pelas iniciativas oficiais, especialmente aquelas articuladas pelo embaixador argentino no Rio de Janeiro, Ramon Carcano (1933-1937), o idealizador dos acordos culturais bilaterais, quanto pela ação cultural exterior (fruto dos empreendimentos de diferentes segmentos da sociedade civil).

Os convênios assinados entre os dois líderes, como parte dos entendimentos visando à maior aproximação "material e espiritual" entre seus países, como se dizia no jargão da época, ocuparam-se das seguintes esferas: comércio e navegação, prevenção e repressão ao contrabando, extradição, navegação aérea, exposições de mostras e vendas de produtos nacionais, turismo, intercâmbio intelectual e artístico, revisão de textos de história e geografia, troca de publicações e o Pacto Antibélico, de Não Agressão e Conciliação que, a princípio, seria um acordo bilateral, mas que ganhou mais prestígio com a adesão do Chile (com reservas), do México, do Paraguai e do Uruguai (FRAGA, 2010).

De acordo com o diplomata de carreira e pesquisador das relações BrasilArgentina, Alessandro Candeas (2010), um dos aspectos mais relevantes dos entendimentos formais entre os dois vizinhos foi justamente a abertura para a adesão de outros países da região, o que, no seu entendimento, revela o potencial estruturante regional contido na relação bilateral. O Convênio de Turismo firmado entre os dois países, é portanto, parte de um contexto mais amplo e favorável à sua realização, ou Revista Eletrônica da ANPHLAC, ISSN 1679-1061, n.15, p. 175-197, jul./dez. 2013. 
seja, integra um conjunto de acordos que fazem parte dos esforços da política externa brasileira e argentina de diversificação da agenda bilateral e promoção do entendimento mútuo. Insere-se também numa conjuntura em que se dá o aumento do interesse e até um relativo amadurecimento da sociedade brasileira em relação à ideia do turismo.

Nos meses que precederam a visita do presidente Justo e assinatura do convênio bilateral de turismo, o primeiro protagonizado pelo Brasil, a 10 de outubro de 1933, percebe-se claramente uma mudança no status do turismo nas páginas do jornal paulistano Folha da Manhã. No momento em que o projeto do convênio estava em elaboração pela Embaixada Argentina no Rio de Janeiro, o jornal conseguiu compreender a ambiência favorável ao turismo e o papel estratégico da atividade para o estreitamento das relações entre Brasil e Argentina. Foi nesse período que se verificou o deslocamento do assunto das últimas páginas, inscrito na seção de esportes em pequenas notas, para as páginas iniciais, os editoriais, as colunas dedicadas às crônicas de escritores brasileiros, os quadrinhos e até a primeira página, quando o turismo assumiu lugar na manchete principal da capa.

Na edição de 13 de julho de 1933, o estreitamento das relações entre Brasil e Argentina pelo turismo foi destaque duas vezes na primeira página. Na manchete principal, em letras garrafais, lia-se: "O turismo vai contribuindo para a obra de aproximação argentino-brasileira". O segundo destaque dado ao assunto na capa do jornal tinha como manchete: "Vêm ao Brasil 250 turistas da Argentina".

O convênio bilateral de turismo, firmado em 1933 e promulgado pelo Decreto $n$. 24.393, de 13 de junho de 1934, contém oito artigos, elaborados em nome do conhecimento e de uma melhor compreensão mútua de brasileiros e argentinos. As principais medidas previstas por esse instrumento foram: a abolição da cobrança de impostos de entrada e saída para turistas procedentes de um desses países com destino ao outro; a redução do número de documentos exigidos, resumindo-se ao passaporte nacional (individual ou coletivo) e ao atestado sanitário; o reconhecimento do direito de livre trânsito dos veículos de turismo provenientes da outra parte em todo o território nacional; a construção das bases de um regime aduaneiro similar aos dois países, no que

Revista Eletrônica da ANPHLAC, ISSN 1679-1061, n.15, p. 175-197, jul./dez. 2013. http://revista.anphlac.org.br/ 
se refere à bagagem dos turistas de ambas as partes; a possibilidade dos governos recorrerem à colaboração das organizações turísticas do país ${ }^{5}$.

Não é difícil deduzir que o representante oficial brasileiro para o turismo seria, então, o Touring Club do Brasil ${ }^{6}$. Ainda com referência aos termos do Convênio, qualquer outro Estado americano poderia a ele aderir, desde que os demais signatários estivessem de acordo, fazendo lembrar as observações de Candeas (2010) sobre o potencial estruturante regional dos acordos Brasil-Argentina.

O jornal carioca Correio da Manhã (12/10/1933) deu destaque à assinatura do convênio, sublinhando a importância estratégica do turismo para o estreitamento das relações políticas entre os dois povos:

A questão do turismo foi objeto de um dos tratados concluídos entre os governos da Argentina e do Brasil, para assinalar a presença, entre nós, do Presidente Justo.

(...)

Há, assim a necessidade de orientar e estimular as viagens, tanto de cá para lá como de lá para cá. O turismo, neste nosso caso, entra em função também na política. Não é senão pelo mútuo conhecimento dos povos que se forma o ambiente de que precisam os governos para concluir sua obra de cooperação internacional.

(...)

No dia em que o argentino vier ao Brasil e o brasileiro for à Argentina com a mesma simplicidade como hoje o carioca vai a São Paulo e o paulista vem ao Rio, teremos verdadeiramente completado não só o trabalho de aproximação, mas de identificação, de nossos dois povos. O primeiro passo foi dado. Não resta senão continuar. (p.6)

Entretanto, havia um certo descompasso entre os termos do Convênio para o Fomento do Turismo e a prática nos portos, aeroportos e fronteiras, no que se referia ao trânsito de brasileiros e argentinos de um país ao outro. Episódios constrangedores, envolvendo a exigência de documentos adicionais não previstos no acordo, geraram grande desconforto e movimentaram as chancelarias dos dois países, a ponto de ser

\footnotetext{
${ }^{5}$ O governo brasileiro comprometia-se em envidar esforços para promover uma federação nacional dessas organizações, ou poderia aceitar alguma das já existentes como sua colaboradora, enquanto o governo argentino atribuiu esse papel à Federación Sul Americana de Turismo, com sede em Buenos Aires.

${ }^{6}$ A decisão de aceitar o TCB como entidade turística, capaz de cooperar para os fins estabelecidos no artigo VI do convênio, foi anunciada pelo Ministério das Relações Exteriores, em agosto de 1934, e pouco depois, levada ao conhecimento do governo argentino. AHI-RJ. Convênio brasileiro-argentino para o fomento do turismo. Ofício do MRE, datado de 17 de agosto de 1934, ao presidente do Touring Club, Octavio Guinle. Classificação: 540.60 (41). Maço 36198, 2 p.
}

Revista Eletrônica da ANPHLAC, ISSN 1679-1061, n.15, p. 175-197, jul./dez. 2013. 
assinado, em fevereiro de 1941, um acordo interpretativo dos termos do Convênio, por meio de troca de notas entre o embaixador do Brasil na Argentina, José de Paula Rodrigues Alves e o ministro das Relações Exteriores e Culto da Argentina, Guillermo Rothe. Ficava combinado, assim, que a cédula de identidade oficial também teria o mesmo efeito do passaporte.

Em 1934, foram criados o Instituto Cultural Argentino-Brasileño, em Buenos Aires, com filiais em Córdoba e Rosário, e o Instituto Brasileiro-Argentino de Cultura, no Rio de Janeiro, com filiais em São Paulo e Porto Alegre. Conforme Santos (2009), os institutos culturais, com representações em importantes cidades do Brasil e da Argentina, marcaram um novo momento na história das relações entre os dois países, inserindo a dimensão cultural na agenda dessas nações como fator relevante para a execução dos seus projetos políticos e econômicos. Era papel desses institutos estimular o conhecimento sobre o outro, fomentando a divulgação da língua, da literatura e da história e geografia nacionais no país vizinho, e estreitando o intercâmbio acadêmico, artístico, esportivo e científico entre ambos.

Santos (2009) destaca que essas atividades, que procuraram fomentar a cooperação cultural entre Argentina e Brasil, não se restringiram apenas à participação de políticos e intelectuais, envolvendo vários setores da sociedade civil. Diversas solenidades e rituais cívicos foram protagonizados por esses institutos, incluindo a inauguração de bustos de personalidades da nação amiga num e noutro país, visitas de cordialidade e cerimônias cívicas.

Sem dúvida, um dos setores mais beneficiados pelo estreitamento dessas relações favorecidas pelos institutos culturais foi o turismo. Foram promovidas viagens para a participação em congressos científicos, excursões turísticas à outra nação, concursos culturais voltados para os estudantes dos dois países, cuja premiação era uma viagem ao vizinho, entre outras atividades.

As iniciativas oficiais, com o uso instrumental da cultura para propaganda e influência, ganharam forte impulso a partir do convênio bilateral de turismo de 1933 e foram seguidas por vários outros atos internacionais, de alcance multilateral. É o caso

Revista Eletrônica da ANPHLAC, ISSN 1679-1061, n.15, p. 175-197, jul./dez. 2013. http://revista.anphlac.org.br/ 
do acordo sobre turismo, negociado pelo Itamaraty entre as municipalidades do Rio de Janeiro, São Paulo, Santos, Buenos Aires e Montevidéu, em setembro de $1935^{7}$.

Tendo Lourival Fontes, então diretor geral de turismo da Prefeitura do Rio de Janeiro e o intendente de Buenos Aires, Mariano de Vedia y Mitre, como principais negociadores, o instrumento previa a união das forças dos maiores destinos turísticos da América do Sul, para um programa de turismo e propaganda comuns, envolvendo abastados turistas da América do Norte.

Nos termos do acordo, em sua Cláusula Segunda, os signatários objetivavam promover doze viagens anuais entre Nova Iorque e as cinco cidades do Atlântico Sul, e posteriormente estender a experiência ao mercado inglês. A excursão duraria 30 dias, sendo quinze no Rio de Janeiro, São Paulo e Santos e os outros quinze dias em Buenos Aires e Montevidéu. A propaganda das viagens em jornais americanos e ingleses correria por conta dos municípios. O acordo teria vigência de um ano. Em sua última cláusula (VIII), permitia a adesão de municípios chilenos, como Santiago e Valparaíso, e outras cidades do continente que dele quisessem tomar parte, desde que oferecessem programas turísticos facultativos.

A iniciativa dos gestores das principais cidades turísticas da América do Sul funcionava como uma estratégia de cooperação para ampliar as chances de captação do turista estrangeiro. Preferiu-se investir em dois dos mais importantes centros capitalistas, com grandes interesses na América do Sul, que estavam também entre os principais países emissores do turismo mundial. A propaganda seria direcionada a um público de maior poder aquisitivo, com a finalidade clara de atrair um seleto grupo de turistas, com alto padrão de consumo. Além disso, o acordo serviria também para estreitar os entendimentos entre as nações proponentes, no que se refere à organização do turismo entre o Brasil e o rio da Prata.

Não há indícios de que as 24 excursões previstas no acordo tenham de fato se efetivado, mas a intencionalidade do ato multilateral pode nos dizer algo sobre o pensamento e as políticas de turismo na América do Sul na época. Situado no seu contexto, o acordo deixa claras as intenções de ganhos econômicos para as partes

\footnotetext{
${ }^{7}$ AHI-RJ. Acordo sobre turismo. Ofício confidencial $\mathrm{n}^{\circ}$ EC 90, enviado a Pedro Ernesto (prefeito do Distrito Federal), pelo chanceler brasileiro José Carlos de Macedo Soares, em 23 de setembro de 1935. Classificação: 540.60 (41). Lata 834, Maço 12253.

Revista Eletrônica da ANPHLAC, ISSN 1679-1061, n.15, p. 175-197, jul./dez. 2013. 
promotoras e evidencia o protagonismo político (e a liderança) de Brasil e Argentina na organização do turismo sul-americano, respaldada pela ideologia do turismo como fator de união dos povos do continente.

Acrescenta-se que, em junho daquele mesmo ano (1935), no âmbito da Conferência Comercial Pan-americana, foram assinadas em Buenos Aires a Convenção do Passaporte Pan-americano de Turismo e de Passaportes de Trânsito para Veículos e a Convenção sobre Trânsito de Aviões, tendo sido criadas também juntas pan-americanas de comércio. Esses instrumentos, sem dúvida, fomentaram os debates sobre integração regional e incremento da economia pela via do turismo pan-americano.

No Itamaraty, foi localizada ainda outra iniciativa bastante ousada da política externa brasileira, especialmente sob o ponto de vista da integração continental. Trata-se do Convênio de Turismo, envolvendo Brasil, Argentina, Uruguai, Paraguai e Bolívia, firmado durante a Conferência Regional dos Países do Prata, em janeiro-fevereiro de 1941, que teve ainda a participação do Chile, do Peru e dos Estados Unidos como observadores. Os termos do convênio assemelham-se bastante àquele realizado entre Brasil e Argentina, o primeiro na América do Sul, em 1933. A minuta do acordo, um documento ainda desconhecido na literatura turística e historiográfica, trata, em suma, da criação de facilidades ao trânsito turístico entre os cidadãos dos países signatários, dentre elas, a supressão do pagamento de impostos de entrada e trânsito dos turistas dessas nacionalidades, e admite o aceite de documento de identidade em lugar do passaporte $^{8}$.

De todos os lados, cresciam as iniciativas que visavam à cooperação turística entre os países platinos, como estratégia de aproximação cultural e também comercial. É muito interessante o caso da Turismar, uma nova organização de turismo argentina, inaugurada junto com as festividades pelo Dia da Pátria, em 9 de julho de 1935. No discurso de estreia, testemunhado pelo embaixador brasileiro e transmitido pela Radio Fenix em cadeia internacional, o diretor-gerente do novo empreendimento turístico referiu-se à amizade com o Brasil e ao interesse no intercâmbio turístico entre as duas nações, o que foi reforçado numa série de documentos enviados por ele ao Itamaraty.

\footnotetext{
${ }^{8} \mathrm{O}$ convênio não consta no acervo da Divisão de Atos Internacionais do Itamaraty, disponível na Internet. Para acesso ao mesmo, no original, datilografado, recorrer ao arquivo físico do Museu do Itamaraty, no Rio de Janeiro.

Revista Eletrônica da ANPHLAC, ISSN 1679-1061, n.15, p. 175-197, jul./dez. 2013. 
Num deles, o missivista informava que estava em curso a segunda excursão turística ao Brasil, pedia atenção especial aos turistas portenhos, declarando esperar que voltassem ao Brasil tão propagandistas do país, quanto o eram os responsáveis pela empresa. Conforme seu diretor geral:

\begin{abstract}
Ahora que ya está em marcha este organismo captador de simpatias a la bella tierra carioca, esperamos que pronto se verán sus resultados, y nosotros tendremos la satisfacción de la obra cumplida, com lo que nos sentiremos pegados suficientemente de nuestro trabajo. ${ }^{9}$
\end{abstract}

Noutro trecho dessa carta, o autor enfatiza o interesse da empresa Turismar na promoção da amizade entre os dois povos, mais do que nos benefícios econômicos ou de utilidade que pudessem ser capitalizados. Curiosamente, à véspera da inauguração da Turismar, o mesmo remetente havia escrito que "Brasil tiene en nosostros un agente propagador tan entusiasta que espera merecer 'bien publico' de las autoridades del país de los caballeros: Brasil" ${ }^{\prime 10}$.

Pouco tempo depois da assinatura do convênio de turismo com os argentinos e do incremento do intercâmbio bilateral, foi a vez dos brasileiros acordarem com os uruguaios as bases para um convênio de turismo, posto nos mesmos termos daquele firmado com a Argentina. Embora o primeiro admitisse a adesão de outras nações regionais interessadas, o caminho escolhido pelos artífices foi a criação de um novo ato bilateral, que também admitia a participação de outros Estados. O novo convênio de turismo envolvendo o Brasil como um dos protagonistas na América do Sul foi assinado a 20 de dezembro de 1933, ratificado em 21 de julho de 1937 e promulgado em agosto desse mesmo ano. Do mesmo modo que ocorrera com o caso argentino, a assinatura do

\footnotetext{
${ }^{9}$ Em livre tradução: "Agora que está em marcha este organismo captador de simpatias à bela terra carioca, esperamos que logo se vejam seus resultados, e nós teremos a satisfação da obra cumprida, com o que nos sentiremos suficientemente pagos pelo nosso trabalho". AHI-RJ. Correspondência enviada por Roberto Arata em 11 de julho de 1935. Classificação: 540.60 (41). Lata 1123, Maço 22205.

${ }^{10}$ Em livre tradução: "O Brasil tem em nós um agente propagador tão entusiasta que espera merecer [o reconhecimento de] 'bem público' das autoridades do país dos cavalheiros: Brasil”.

AHI-RJ. Correspondência enviada por Roberto Arata em 8 de julho de 1935. Classificação: 540.60 (41). Lata 1123, Maço 22205.

Revista Eletrônica da ANPHLAC, ISSN 1679-1061, n.15, p. 175-197, jul./dez. 2013. 
convênio de turismo com o Uruguai inscrevia-se num conjunto de diversos acordos protocolares firmados entre as partes ${ }^{11}$.

Em maio de 1935, Getúlio Vargas retribuiu a visita do chefe de Estado argentino, ocasião em que fez a abertura, ao lado de Justo, da Conferência Comercial Pan-Americana. Na era republicana, somente Campos Sales havia feito uma visita oficial ao país vizinho, em 1900, retribuindo a visita de Julio A. Roca no ano anterior.

O Automóvel Clube Argentino tomou parte da Comissão de Homenagem a Vargas, emprestando a sua sede social para a logística e organização dos eventos comemorativos da visita do presidente brasileiro, servindo, inclusive, como local de hospedagem da comitiva presidencial. Na edição de janeiro de 1935 de sua revista, a instituição justificava o interesse em exteriorizar sua simpatia pela visita de Vargas, pois esta "constituye un vínculo más, destinado a estrechar las ya cordiales relaciones de dos pueblos hermanos" $" 12$. No número seguinte, a revista publicou em duas páginas uma matéria intitulada De Montevideo a Rio de Janeiro em Automóvil, apresentando aos leitores possíveis rotas de integração do turismo continental.

A presença de Vargas na Argentina inscreveu-se num contexto de maiores entendimentos entre as duas nações, quando ambas estavam envolvidas na mediação do conflito entre Paraguai e Bolívia, conhecido como Guerra do Chaco (1932-1935), encerrado poucas semanas depois da visita do presidente brasileiro à capital portenha (FRAGA, 2000). A atuação da diplomacia brasileira junto com a argentina para pôr termo ao conflito teve uma boa repercussão e projetou ainda mais o chanceler argentino Saavedra Lamas, agraciado com o Prêmio Nobel da Paz em 1936, pela sua mediação na Guerra do Chaco. Lamas contrariou as intenções de Washington de arbitrar a mediação do problema e projetou a imagem prestigiosa acerca da capacidade do Estado argentino e dos demais mediadores da América do Sul, incluindo o Brasil, na resolução de conflitos na esfera regional.

\footnotetext{
${ }^{11}$ São eles: Convênio para a fixação do Estatuto jurídico da Fronteira e respectivo Protocolo Adicional, Convênio de intercâmbio artístico, Acordo para a permuta de publicações, Convênio para o fomento do turismo e Convênio sobre exposições de amostras e vendas de produtos nacionais. A adesão ao convênio bilateral firmado entre Brasil e Argentina chegou a ser anunciada pela Embaixada do Uruguai e saudada pelo Itamaraty em outubro de 1934, mas não foi efetivada.

${ }^{12} E m$ tradução livre: "constitui um vínculo a mais, destinado a estreitar as já cordiais relações de dois povos irmãos". La adhesion del ACA a los festejos em honor del Presidente del Brasil, Dr. Getúlio Vargas. Automovilismo, Ano XV, n 184, s.p., janeiro de 1935.
}

Revista Eletrônica da ANPHLAC, ISSN 1679-1061, n.15, p. 175-197, jul./dez. 2013. 
Novos acordos foram firmados entre Brasil e Argentina, de alcance político, econômico e cultural. Citam-se o Tratado de Comércio e Navegação, o Convênio sobre Lutas Civis, o Convênio para o Fomento de Intercâmbio de Professores e Estudantes, o protocolo sobre extradição, o protocolo sobre a construção da ponte entre Uruguaiana e Paso de los Libres ${ }^{13}$ e o Convênio para Visitas de Técnicos Fitossanitários.

O intercâmbio de acadêmicos, intelectuais e estudantes fora acompanhado com atenção pelos jornais dos dois países, que noticiavam a presença das caravanas de professores e alunos no país vizinho, bem como dos intelectuais e artistas de prestígio. Não foram raras as vezes em que esses embaixadores da amizade entre os dois povos, como eram tratados, foram recepcionados pelo presidente da república do país visitado, atraindo a atenção de importantes periódicos, como o argentino La Nacióne os brasileiros Folha da Manhã (SP) e Jornal do Brasil (RJ).

Esse movimento também chamou a atenção da revista Brasil, Paiz de Turismo, que, em fevereiro de 1937, destacou o interesse da Comissão Revisora dos Textos de História e Geografia, na promoção de visitas anuais ao Brasil de professores, pesquisadores e também estudantes argentinos com os melhores desempenhos. Essas visitas eram promovidas e incentivadas por institutos culturais, como o Instituto Argentino-Brasileiro, que tiveram um importante papel no intercâmbio cultural e turístico entre os dois povos.

O peso da cooperação cultural foi reforçado, como demonstrou Raquel Paz dos Santos (2008),como estratégia de uma efetiva aproximação entre os povos dos dois países e de sustentação da ideologia integracionista, operada no plano mental a partir da formulação de uma identidade regional. Essa, por sua vez, se nutria da ideia de uma suposta raça latino-americana, sustentada cientificamente no processo de reelaboração de uma cultura histórica latino-americana, com a revisão dos conteúdos dos livros de história e de geografia, por exemplo.

\footnotetext{
${ }^{13} \mathrm{~A}$ inauguração da ponte internacional sobre o rio Uruguai, ligando a cidade argentina de Paso de Los Libres à brasileira Uruguaiana, se deu a 12 de outubro de 1945, com uma grande solenidade, que contou com a participação dos presidentes Perón e Dutra. Chamada oficialmente de Ponte Internacional Getúlio Vargas-Augustín Pedro Justo, a construção foi a primeira via de comunicação terrestre (rodoviária e ferroviária) entre os dois países e foi considerada à época a maior obra de engenharia da América Latina, com 1.419 metros de extensão.
}

Revista Eletrônica da ANPHLAC, ISSN 1679-1061, n.15, p. 175-197, jul./dez. 2013. 
A nova amizade Brasil-Argentina evocava uma herança cultural comum e as afinidades físicas e geográficas entre os dois povos, agora irmãos. Essa retórica era comum também à imprensa, chegando o Jornal do Brasil, em 23 de maio de 1934, à página 4, a noticiar o estreitamento dos laços fraternos de uma "amizade secular" entre brasileiros e argentinos, por ocasião da ratificação, em Buenos Aires, dos convênios firmados no Rio de Janeiro no ano anterior, dentre eles, o de turismo.

Esses discursos procuravam contornar as idiossincrasias históricas, como a desconfiança mútua e o sentimento de superioridade dos argentinos em relação aos brasileiros, tanto do ponto de vista cultural quanto étnico (SANTOS, 2008). Estavam relacionados também às estratégias de fortalecimento do movimento pan-americanista $\mathrm{e}$ às disputas por hegemonia dentro desse próprio movimento. $\mathrm{E}$ o turismo, nesse contexto, era visto como uma atividade bastante propícia para gerar esses entendimentos entre os povos da América ou, num projeto ainda mais particular de aproximação, entre as duas principais nações da América do Sul.

\section{Considerações finais}

Entre a cordialidade e a competitividade, Brasil e Argentina muito dialogaram nas primeiras décadas do século XX, particularmente nos anos 1920 e 1930, procurando estimular o conhecimento mútuo e a amizade entre as duas nações. O turismo foi, seguramente, uma importante ferramenta mobilizada pelos agentes governamentais e pela sociedade civil, na formulação de discursos relacionados à aproximação bilateral e ao protagonismo dos dois países na organização de um turismo pancontinental. Essa fora uma das principais prerrogativas da Federação Sul-Americana de Turismo, que teve no Touring Club dos dois países os seus principais artífices, com a chancela dos governos de Argentina e Brasil.

O incremento do turismo continental deveu-se também ao desenvolvimento de novas rotas alternativas às viagens à Europa; à estratégia de utilização do turismo como um instrumento de sustentação política e econômica do projeto de construção da "PanAmérica" (uma grande área imaginada no plano discursivo como contínua e homogênea); e às iniciativas de aproximação bilateral entre Brasil e Argentina, no

Revista Eletrônica da ANPHLAC, ISSN 1679-1061, n.15, p. 175-197, jul./dez. 2013.

http://revista.anphlac.org.br/ 
sentido de assumir a organização e a liderança do turismo na América do Sul, o que em alguns casos também incluía o Uruguai.

Sem dúvida, nesse período houve um intenso intercâmbio cultural e turístico entre cidadãos dos dois países, movidos pelo interesse de conhecimento mútuo e pelas relativas facilidades de entrada no país vizinho, favorecidas pelos instrumentos legais que incentivavam o aumento do trânsito turístico entre as duas nações.

Da Argentina, vieram para o Brasil estudantes, professores, artistas, cientistas e intelectuais, favorecidos pelos intercâmbios culturais, científicos e artísticos promovidos pelas duas nações vizinhas e pelo conjunto da nova legislação que regia a mobilidade entre os dois países, em projetos paralelos ou até complementares à Política da Boa Vizinhança do Tio Sam. Ainda assim, muitos passaram por inúmeros embaraços burocráticos, provocados pelas dificuldades de implantação das novas facilidades legais de entrada no território vizinho, oferecidas a quem tivesse a condição de "turista".

Novos estudos sobre a integração latino-americana pela via do turismo merecem ser desenvolvidos, no intuito de pensar como esse objeto ainda tão pouco estudado, o turismo, foi e continua sendo relevante para o desenvolvimento das relações políticas, econômicas e, sobretudo, culturais entre os países.

\section{Arquivos e bibliotecas}

Archivo del Ministerio de Relaciones Exteriores y Culto - correspondência diplomática trocada entre a Embaixada Argentina no Rio de Janeiro e o governo argentino (19331946).

Archivo Histórico de Cancillería (Buenos Aires) - biblioteca do Arquivo - livros e artigos sobre o peronismo, o Brasil e os Estados Unidos.

Biblioteca de Turismo/Centro de Documentación Turística de la Ciudad de Buenos Aires - livros acadêmicos e periódicos de turismo.

Biblioteca del Automovil Club Argentino(Buenos Aires) - revista Automovilismo (1933-1946)

Biblioteca Nacional de la República Argentina (Buenos Aires) - periódicos de turismo - Hemeroteca (1930-1946); dicionários, dicionários históricos, bibliografia de história da Argentina e de turismo.

Arquivo Histórico do Itamaraty (Rio de Janeiro) - Correspondência diplomática entre Brasil e Argentina (1928-1946); correspondência das embaixadas do Brasil na Europa, África do Sul e Estados Unidos; acordos e convênios bilaterais entre Brasil e Argentina;

Revista Eletrônica da ANPHLAC, ISSN 1679-1061, n.15, p. 175-197, jul./dez. 2013. 
correspondências trocadas entre o Ministério das Relações Exteriores e as organizações de turismo brasileiras.

\section{Referências}

AUTOMOVILISMO (Automóvil Club Argentino). Buenos Aires, 1933-1946.

AZEVEDO, Francisca; KNAUSS, Paulo. In: A VISÃO DO OUTRO: Seminário Brasil-Argentina. Brasília: FUNAG, 2000. p. 641-662.

BRASIL. Commemoração do Primeiro Centenário da Independência política do Brasil - 1822-1922. Programma da Commemoração. Regulamento Geral da Exposição Nacional de 1922. Rio de Janeiro: Papelaria Americana, 1921. Arquivo do CPDOC.

BRUNO, Perla. Tradición y modernidad em la concepción del território turístico en el litoral bonaerense, Argentina - 1920-1950. In: Revista Iberoamericana de Urbanismo, n.2, p. 4-16, 2009.

BRUNO, Perla Ana; LEMME, Adrián Domingo. Turismo, território y paisaje em la costa bonaerense argentina - 1920-1940. In: Estudios y Perspectivas in Turismo, v.19, n.1, p. 45-62, jan/fev 2010.

CANDEAS, Alessandro Warley. A integração Brasil-Argentina: história de uma ideia na "visão do outro". Brasília: FUNAG, 2010.

COOMBS, Philip. The fourth dimension of foreign policy. New York: Harper \& Row Publishers, 1964.

DONGHI, Tulio Halperín. Historia contemporánea de America Latina. Buenos Aires: Alianza, 2010.

1975.

História da América Latina. São Paulo: Círculo do Livro,

FAUSTO, Boris; DEVOTO, Fernando. Brasil e Argentina: um ensaio de história comparada (1850-2002). São Paulo: Editora 34, 2004.

FERREIRA, Roberta Maria Lima. A política brasileira de expansão cultural no Estado Novo (1937-1945).Rio de Janeiro, 2006. Dissertação (Mestrado em História) Universidade do Estado do Rio de Janeiro, Programa de Pós-Graduação em História, Rio de Janeiro, 2006.

FRAGA, Rosendo. Los acuerdos Vargas-Justo; 1933-1935. In: A VISÃO DO OUTRO: Seminário Brasil-Argentina. Brasília: FUNAG, 2000. p. 401-421.

GUCCI, Guillermo. A vida cultural do automóvel. Percursos da modernidade cinética. Rio de Janeiro: Civilização Brasileira, 2004.

GUIMARÃES, Valeria Lima. Por una historia comparada del turismo en Brasil y en la Argentina: um análisis sobre la formación dos discursos turísticos y surelación com el poder. In: Taller Internacional de História y Turismo, 1, Anais...Mar del Plata: Universidad Nacional de Mar del Plata, 2012. (CD-ROM).

Revista Eletrônica da ANPHLAC, ISSN 1679-1061, n.15, p. 175-197, jul./dez. 2013. 
HERZ, Monica. A dimensão cultural das relações internacionais e os atores não governamentais. Contexto internacional. In: Revista Contexto Internacional, Rio de Janeiro: Pontifícia Universidade Católica do Rio de Janeiro, v. 8, n.8, p. 69-81, 1988.

JESUS, Diego S. Vieira; GUIMARÃES, Valeria Lima. Muito além da festa: o VI SulAmericano e as relações internacionais no Centenário da Independência do Brasil. In: SANTOS, João Manuel C. M.; MELO, Victor (Orgs.).1922: celebrações esportivas do centenário. Rio de Janeiro: 7 Letras, 2012. p. 37-57.

LESSA, Mônica Leite. Relações culturais internacionais. In: MENEZES, Lená Meeiros de; ROLLEMBERG, Denise; MUNTEAL FILHO, Oswaldo (Orgs.). Olhares sobre o político: novos ângulos, novas perspectivas. Rio de Janeiro: EDUERJ/FAPERJ, 2002. p. 11-25.

MACHADO, Marcello de Barros Tomé. A modernidade no Rio de Janeiro: construção de um cenário para o turismo. Rio de Janeiro: Secretaria Municipal das Culturas, 2008.

MOURA, Gerson. Tio Sam chega ao Brasil: a penetração cultural americana. São Paulo: Brasiliense, 1984. Coleção Tudo é História.

O TURISMO argentino-brasileiro. In: Correio da Manhã, p. 6, 12 de outubro de 1933.

PASTORIZA, Eliza. La conquista de las vacaciones: breve historia del turismo em la Argentina. Buenos Aires: Edhasa, 2011.

; PEDETTA, Marcelo. "Lo que elpueblonecesita". Turismo social y Peronismo. Argentina, 1945-1955. In: Études caribéennes. Le tourisme en Amérique latine: enjeux et perspectives de développement, n.13-14, p. 1-19, Déc. 2009.

PESSOA, Epitácio. À Nação. O governo de 1919-1922. Rio de Janeiro: Imprensa Nacional, 1922.

PIGLIA, Melina. Asociaciones civiles y estado en los años veinte: intervenciones del Automóvil Club Argentino. In: Estudios Interdisciplinarios de America Latina y el Caribe, v.19, n.2, p.119-140, jul-dez. de 2008. Disponível em: <http://www1.tau.ac.il/eial/index.php?option=com_content\&task=view\&id=263\&Itemid=174>. Acesso em: 14/09/2012.

PIGLIA, Melina. Automóviles, Turismo y carreteras como problemas públicos: los clubes de automovilistas y la configuración de las políticas turísticas y viales em la Argentina (1918-1943). Buenos Aires, 2009. Tese (Doutorado em História) - Facultad de Filosofia y Letras, Universidad de Buenos Aires. Buenos Aires, 2009.

La incidencia del Touring Club y del ACA en la construcción del turismo como cuestión pública (1918-1929). In: Estudios y Perspectivas en Turismo, v.17, p. 51-78,2008.

Disponível em: <http://www.scielo.org.ar/pdf/eypt/v17n1/v17n1a03.pdf>. Acesso em: 04/12/2011.

REPÚBLICA ARGENTINA. 100 años de turismo argentino. Buenos Aires: Ministério do Turismo/ Secretaria de Turismo, 2007. Disponível em: <http://www.cienaniosdeturismo.gov.ar/uploads/file/136boletin100a\%C3\%B1os.pdf>.A cesso em: 4/08/2012.

Revista Eletrônica da ANPHLAC, ISSN 1679-1061, n.15, p. 175-197, jul./dez. 2013. 
SANTOS, Raquel Paz dos. Brasil e Argentina: imagens e percepções da diplomacia. In: Encontro da Associação Nacional de Pesquisadores e Professores de História das Américas Anais Eletrônicos, 4, Maringá: ANPHLAC, 2004.

Relações Brasil-Argentina: a cooperação cultural como instrumento de integração regional. In: Estudos Históricos, v.22 , n.44, p. 355-375, juldez de 2009.

Um olhar sobre o país vizinho: representações do Brasil e da Argentina no contexto das relações diplomática (1930-1954). Niterói, 2008. Tese (Doutorado em História) - Programa de Pós-Graduação em História Social, Universidade Federal Fluminense. Niterói: 2008.

SARAIVA, José Flávio Sombra. História das relações internacionais: o objeto de estudo e a evolução do conhecimento. Brasília: IBRI, 2001.

SCHLÜTER, Regina. El turismo en Argentina - del balneário al campo. Buenos Aires: Centro de Investigaciones y Estudios Turísticos (CIET), 2003.

SUPPO, Hugo Rogelio; LESSA, Mônica Leite. O estudo da dimensão cultural nas Relações Internacionais: contribuições teóricas e metodológicas. In: LESSA, Mônica Leite; GONÇALVES, Wiliams da Silva (Orgs.). História das relações internacionais: teorias e processos. Rio de Janeiro: EDUERJ, 2007. p.223-250

TURISMO (Revista do Touring Club Argentino). 1933-1946.

TOURING CLUB DO BRASIL. Uma memória dos tempos da mão inglesa. Disponível em: <www.touring.com.br/historia.php>. Acesso em: 28/05/2013.

VISITA anual da Argentina ao Brasil. In: Brasil, Paiz de Turismo, Ano III, n. XI, s.p, fevereiro de 1937.

WALLINGRE, Noemí. Historia del turismo argentino. Buenos Aires: Ediciones turísticas, 2007.

Revista Eletrônica da ANPHLAC, ISSN 1679-1061, n.15, p. 175-197, jul./dez. 2013.

http://revista.anphlac.org.br/ 